\title{
Letter to Editor-NCIC FPC Filing Sequence Formula
}

\author{
Andres J Washington* \\ Fingerprint Geometric Analysis, Post Office Box 165 Bronx, NY 10451-0165, USA
}

\section{Dear Dr. Ishikawa,}

Together as members of the International Association for Identification and the Medical Community, we share an interest in the friction ridge formation appearing on the person of individuals. Consider the NCIC FPC Filing Sequence Formula. This application can be used in a study on the combination of fingerprint patterns and their frequency for each digit. It was designed as applicable to genetics or any discipline which encompasses the phenomenon of the human physical structure; an advanced computational formula for educational institutions and the criminal justice system.

Why is the frequency of patterns important? In a physical study the type and frequency of a given pattern provides an insight into the potential of the individual. This is because fingerprints are a result of our genetic make-up and our intelligence is as well. Further, the medical community has noted that much of the development of the brain takes place simultaneously with the dermatoglyphic development. To exemplify, an individual who displays an accidental whorl which encompasses two different and distinct patterns equally maintains two different and distinct abilities. The abilities are separate but are interrelated when the aforementioned pattern appears on a single digit. Please feel free to reach me should you have any questions regarding this subject [1,2].

Sincerely,

Andres J. Washington

\section{References}

1. Washington AJ (2016) The Hand Prints of Dr. Albert Einstein. J Forensic Sci \& Criminal Inves 1: 555551.

2. Washington AJ (2017) Fingerprint Geometric Analysis. J Forensic crime investi 1: 102
Copyright: (C2018 Washington AJ. This is an open-access article distributed under the terms of the Creative Commons Attribution License, which permits unrestricted use, distribution, and reproduction in any medium, provided the original author and source are credited.
Correspondence to: Andres J. Washington, Fingerprint Geometric Analysis, Post Office Box 165 Bronx, NY 10451-0165, USA, Tel: +1 914960 3526; E-mail: director@dermatoglyphics.com

Received: February 08, 2018; Accepted: February 15, 2018; Published: February 18,2018 